\title{
Manganese Doping Stabilizes Perovskite Light-Emitting Diodes by Reducing Ion Migration
}

\author{
Moritz H. Futscher, Mahesh K. Gangishetty, Daniel N. Congreve, and Bruno Ehrler* \\ Cite This: https://dx.doi.org/10.1021/acsaelm.0c00125 \\ Read Online
}

ABSTRACT: Lead-halide perovskite light-emitting diodes have recently emerged as high-performance devices. However, they degrade rapidly. This degradation has been attributed to the mixed ionic-electronic nature of these perovskites. Manganese doping increases the stability of perovskite light-emitting diodes, but the effects of manganese doping on ion migration are not well understood. We use impedance spectroscopy and transient iondrift measurements to study the effect of manganese doping on ion migration in $\mathrm{PEABr}_{0.2} \mathrm{Cs}_{0.4} \mathrm{MA}_{0.6} \mathrm{PbBr}_{3}$ quasi-bulk two-/threedimensional perovskite light-emitting diodes. We find that
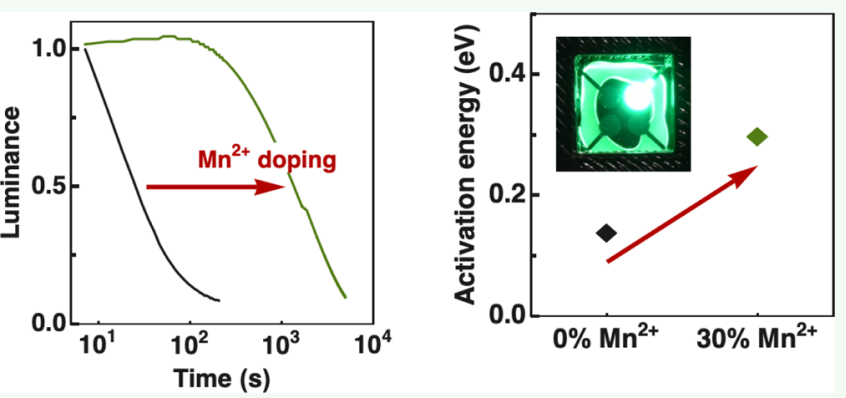
manganese doping enhances the activation energy for ion migration twofold and reduces the diffusion coefficient. These changes in the behavior of mobile ions help us to explain the improved stability in perovskite light-emitting diodes upon manganese doping and lead to a better understanding of the influence of passivating agents on ion migration and thus on the stability of the devices.

KEYWORDS: perovskites, light-emitting diodes, mobile ions, manganese, capacitance, impedance, transient ion drift

\section{INTRODUCTION}

Lead-halide perovskites show great promise for light-emitting applications. Since the first report of a perovskite light-emitting diode (LED) in 2014 with an external quantum efficiency (EQE) of electroluminescence of $1 \%,{ }^{1}$ the EQE has increased to $>20 \%$ using quasi-two/three dimensional $(2 \mathrm{D} / 3 \mathrm{D})$ perovskite structures. ${ }^{2-5}$ While perovskite LEDs show high efficiencies, their progress has so far been hampered by fast device degradation. ${ }^{6}$ Perovskites are mixed electronic-iconic conductors containing mobile ions, and these ions have been linked to the poor stability of perovskite LEDs. ${ }^{6,7}$

Lead-halide perovskites have a chemical formula of $\mathrm{ABX}_{3}$, where the A-site cation typically contains methylammonium, formamidinium, or cesium, with the best-performing devices containing a mixture of these cations. ${ }^{8-10}$ The B-site cation is lead, and the $\mathrm{X}$-site halide is typically a combination of chloride, bromide, or iodide, depending on the desired band gap. $^{11}$

Several strategies involving A-site dopants such as azetidinium and guanidinium have been shown to improve the stability of perovskite-based optoelectronic devices. ${ }^{12-15}$ This increase in stability upon partial cation substitution was recently shown to be due to suppression of ion transport. ${ }^{16}$

In addition to A-site doping, B-site doping has also shown positive effects on both performance and stability of perovskite-based optoelectronic devices. ${ }^{17-23}$ Recently, by introducing manganese $\left(\mathrm{Mn}^{2+}\right)$ into the perovskite, an increase in efficiency, brightness, and stability of perovskite LEDs was observed. $^{21}$ X-ray diffraction and electron paramagnetic resonance measurements suggest that $\mathrm{Mn}^{2+}$ ions are incorporated into the crystal lattice, with $\mathrm{Mn}^{2+}$ replacing $\mathrm{Pb}^{2+}$, resulting in lattice contraction. ${ }^{24-26}$ Enhanced efficiency and brightness have been attributed to reduced nonradiative recombination and evidenced by improved EQEs after doping. ${ }^{21,22}$ However, the origin of the increase in operational stability is still unclear. Using first-principle calculations, Zou et al. found that doping $\mathrm{CsPbBr}_{3}$ quantum dots with $\mathrm{Mn}^{2+}$ increases the formation energy to form a nanocrystal from its isolated atoms and thus significantly improves the thermal stability. ${ }^{17}$ Presumably, this change also affects the behavior of mobile ions, which is one of the main causes for the instability of perovskite LEDs. ${ }^{6}$ The effect on $\mathrm{Mn}^{2+}$ doping on ion migration, however, has not yet been investigated.

To study the effect of $\mathrm{Mn}^{2+}$ doping on mobile ions, we employ impedance spectroscopy and transient ion-drift (TID) measurements on perovskite LEDs. We use $\mathrm{PEABr}_{0.2} \mathrm{Cs}_{0.4} \mathrm{MA}_{0.6} \mathrm{PbBr}_{3}$ quasi-bulk $2 \mathrm{D} / 3 \mathrm{D}$ perovskites, both $\mathrm{Mn}^{2+}$-doped and undoped, to fabricate the LEDs. We find that $\mathrm{Mn}^{2+}$ doping increases the activation energy for ion migration

Received: February 18, 2020

Accepted: May 12, 2020

Published: May 12, 2020 
twofold and reduces the diffusion coefficient, thereby enhancing the stability of perovskite LEDs.

\section{RESULTS AND DISCUSSION}

Device Characteristics and Improved Stability. The LEDs used in this study consist of indium tin oxide/poly (3,4ethylenedioxythiophene)/perfluoro ionomer (ITO/PEDOT/ $\mathrm{PFI} /$ perovskite/TPBi/LiF/Al. Here, PFI is an ionomer that acts as a buffer layer and prevents charge leakage into the device. On top of this, a $\sim 80 \mathrm{~nm}$ thick perovskite is deposited by spin coating the perovskite precursors. To make the doped perovskite layers, we replaced $30 \%$ of $\mathrm{PbBr}_{2}$ with $\mathrm{MnBr}_{2}$ in the precursor solution. The detailed fabrication process can be found in our previous work. ${ }^{21}$

After doping with $\mathrm{Mn}^{2+}$, we observed a striking change in the device performance, similar to our previous work. ${ }^{21}$ From the current density-voltage-luminance curves, a significant reduction in current leakage is observed (Figure 1a). The
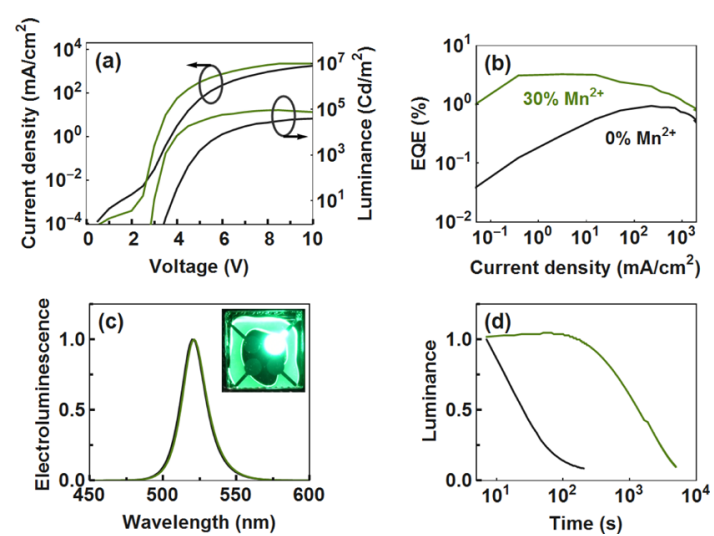

Figure 1. Characteristics of perovskite LEDs. (a) Current densityvoltage-luminance curves, (b) EQE, (c) electroluminescence spectra showing a peak at $520 \mathrm{~nm}$, and (d) operational stability of LEDs operated at a current density of $3 \mathrm{~mA} / \mathrm{cm}^{2}$. The inset in (c) shows a photograph of the LED under operation.

device brightness is increased from 26,000 to $89,800 \mathrm{Cd} / \mathrm{m}^{2}$ after $\mathrm{Mn}^{2+}$ doping. Further, control devices showed a maximum EQE of $0.9 \%$, which is increased to $3.3 \%$ after doping (Figure 1b). Both the devices showed an emission peak at $520 \mathrm{~nm}$, as shown in Figure 1c. Most importantly, the operational stability increased significantly compared to the control devices. The initial luminance for the $\mathrm{Mn}^{2+}$-doped device is $148 \mathrm{Cd} / \mathrm{m}^{2}$ under a constant current density of 3 $\mathrm{mA} / \mathrm{cm}^{2}$, and it took $22 \mathrm{~min}$ to reach $50 \%$ of initial value. The control device, however, showed lower luminance at $t=0$ and decreased to $50 \%$ of the initial value in less than $1 \mathrm{~min}$. This striking increase in operational stability after doping is not limited to only green (bromide) LEDs but also observed in sky blue (chloride bromide) and red (bromide iodide) perovskite LEDs. ${ }^{21}$ To understand the impact of $\mathrm{Mn}^{2+}$ doping, we turned to impedance spectroscopy and TID measurements. A detailed description on how impedance spectroscopy and TID measurements can be used to quantify ion migration in perovskite-based devices can be found in our previous work. ${ }^{27}$

Impedance Spectroscopy. Impedance spectroscopy is a powerful and nondestructive electrical characterization method for studying optoelectronic devices. ${ }^{28-31}$ It is based on applying a small AC voltage with varying frequency $(f)$ to the device and recording the current response. The measure- ment can then be used to obtain the frequency-dependent real $\left(C^{\prime}\right)$ and imaginary parts $\left(C^{\prime \prime}\right)$ of the complex capacitance of the device. Figure 2a,b shows the measured complex
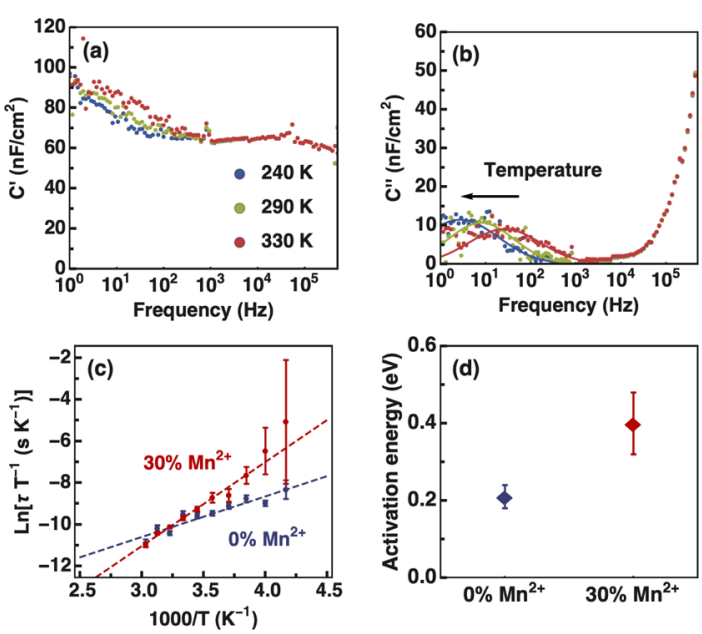

Figure 2. Impedance spectroscopy measurements performed in the dark at 0 V. (a) Real $\left(\mathrm{C}^{\prime}\right)$ and (b) imaginary parts $\left(\mathrm{C}^{\prime \prime}\right)$ of the complex capacitance of the undoped perovskite. (c) Arrhenius plot of the measured time constants for both the $\mathrm{Mn}^{2+}$-doped and undoped perovskite. (d) Effect of $\mathrm{Mn}^{2+}$ doping on the activation energy measured by impedance spectroscopy.

capacitance of the perovskite LED at different temperatures. The low-temperature peak in $\mathrm{C}^{\prime \prime}$ shifts from 26 to $3 \mathrm{~Hz}$ with decreasing temperature from 330 to $240 \mathrm{~K}$ (Figure 2b). At frequencies above $10^{4} \mathrm{~Hz}$, the capacitance decreases because of the series resistance of the device. At frequencies between $10^{3}$ and $10^{4} \mathrm{~Hz}$, the capacitance is related to the geometric capacitance of the device.

The low-frequency peak in Figure $2 \mathrm{~b}$ indicates a relaxation process with a time constant $\tau=1 /(2 \pi f) .{ }^{32}$ To obtain the time constant of the relaxation process, we fit a Gaussian distribution to the low-frequency region. Assuming that the relaxation process is due to the migration of mobile ions, we can obtain the diffusion coefficient with

$$
\tau=\frac{l^{2}}{D}
$$

where $l$ is the diffusion length and $D$ is the diffusion coefficient given by

$$
D=D_{0} \exp \left(-\frac{E_{\mathrm{A}}}{k_{\mathrm{B}} T}\right)
$$

where $E_{\mathrm{A}}$ is the activation energy and $D_{0}=\frac{\nu_{0} d^{2}}{6} \exp \left(\Delta S / k_{\mathrm{B}}\right)$ is a temperature independent prefactor; $\nu_{0}$ is the attempt frequency of an ionic jump, $d$ is the jump distance, and $\Delta S$ is the change in entropy during the jump. ${ }^{27}$ Assuming that the diffusion length is equal to the Debye length, the time constant can be written as

$$
\tau=\frac{\varepsilon_{0} \varepsilon k_{\mathrm{B}} T}{q^{2} N D_{0}} \exp \left(\frac{E_{\mathrm{A}}}{k_{\mathrm{B}} T}\right)
$$

where $\varepsilon_{0}$ is the vacuum permittivity, $\varepsilon$ is the permittivity of the perovskite layer, $k_{\mathrm{B}}$ is the Boltzmann's constant, and $N$ is the effective doping density, which is the product of the mobile ion 

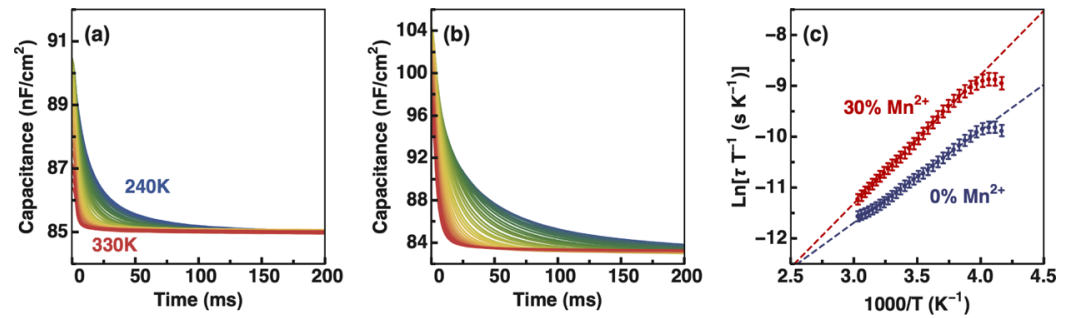

Figure 3. TID measurements for the (a) undoped and (b) $\mathrm{Mn}^{2+}$-doped perovskite. (c) Arrhenius plot of the measured time constants used to obtain the activation energy and the diffusion coefficient for ion migration.

density and the doping density, $q$ is the elementary charge, and $T$ is the temperature. The activation energy can be determined by plotting $\ln (\tau / T)$ as a function of $1000 / T$ on an Arrhenius plot (see Figure $2 \mathrm{c}$ ). For the undoped perovskite LEDs, we get $E_{\mathrm{A}}=0.21 \pm 0.03 \mathrm{eV}$. Upon doping with $\mathrm{Mn}^{2+}$, we find an increase to $E_{\mathrm{A}}=0.40 \pm 0.08 \mathrm{eV}$. This increase is a first indication that the improved device stability may stem from suppressed ion migration.

We extract the activation energy from the low-frequency capacitance, which is commonly assigned to ion migration. ${ }^{31}$ However, additional measurements are needed to attribute the increase in activation energy to a change in ion migration.

The capacitance at low frequencies is highly dependent on the device stack. ${ }^{33}$ In addition to the LED structure, we therefore measure a structure consisting of $\mathrm{NiO}_{X} /$ perovskite/ $\mathrm{C}_{60}$ /bathocuproine (BCP), which is often used for perovskite solar cells. For this solar cell structure, we find a similar increase in $E_{\mathrm{A}}$ from $0.13 \pm 0.01$ to $0.28 \pm 0.06 \mathrm{eV}$ after $\mathrm{Mn}^{2+}$ doping (see Supporting Information Section S1), suggesting that the increase in activation energy is not determined by the interfaces. Therefore, we tentatively assign the increase in activation energy upon $\mathrm{Mn}^{2+}$ doping to a change within the perovskite bulk. We emphasize, however, that the observed changes in impedance measurements can be due to both mobile ions and trap states within the perovskite bulk.

TID. To determine whether the increase in activation energy measured by impedance spectroscopy is due to traps or mobile ions, we use TID measurements. ${ }^{34-37}$ In the case of traps, the application of a bias would lead to charge carriers being trapped at these defect states, changing the capacitance. ${ }^{27}$ After removing the bias, the release of charge carriers from traps would result in a capacitance transient due to a change in the charge density. On the other hand, in the case of mobile ions, the application of a voltage bias would lead to redistribution of ions within the device, as the ions diffuse into the previously depleted region. ${ }^{35}$ After removing the voltage bias, mobile ions would drift toward the interfaces because of the presence of the internal electric field within the device, resulting in a capacitance transient caused by a change in the depletionlayer width. ${ }^{37}$ The difference between the traps and mobile ions is the ratio of timescales. For mobile ions, the capacitance rise is expected to be slower than the decay. ${ }^{38}$ In contrast, in the case of traps, the capacitance rise is much faster than the decay. A detailed description of the expected times can be found in our previous work. ${ }^{27}$ With the inverted solar cell structure, we observe a ratio between rise and decay time characteristics for mobile ions (see Supporting Information Section S2 for details). For the LED structures, the ratio between the rise and decay times points toward a measurement of traps instead. We speculate that mobile ions are not visible in the LED structure because of the high voltage biases required to collapse the depletion region, which leads to a considerable charge injection and hence a large diffusion capacitance. In some cases, this can even result in decomposition of the perovskite into its precursors. ${ }^{39} \mathrm{We}$ therefore use the solar cell structure to quantify mobile ions using TID measurements. Note that for the impedance measurements above, no voltage bias was required, and therefore the detrimental effects observed here for the LED structure are not relevant.

Under the assumptions of (i) a linear electric field, (ii) diffusion negligible against drift, and (iii) the total ion concentration conserved, the capacitance transient can be described with

$$
C(t)=C(\infty) \pm C(\infty) \frac{N_{\text {ion }}}{2 N} \exp \left(-\frac{t}{\tau}\right)
$$

where $C(\infty)$ is the steady-state capacitance, $N_{\text {ion }}$ is the density of mobile ions, and $\tau$ is a time constant given by eq $3 .^{27,34}$

Perovskite permittivity and effective doping density are obtained by impedance spectroscopy measurements and voltage-dependent capacitance measurements (see Supporting Information Section S1 and Section S3).

Figure $3 \mathrm{a}, \mathrm{b}$ shows the capacitance transients following a voltage bias of $1.25 \mathrm{~V}$ applied for $2 \mathrm{~s}$ on the undoped and $\mathrm{Mn}^{2+}$-doped perovskite, measured at $0 \mathrm{~V}$ with a $20 \mathrm{mV}$ ac perturbation at $10 \mathrm{kHz}$. Hall measurements have shown that both $\mathrm{CsPbBr}_{3}$ and $\mathrm{MAPBBr}_{3}$ perovskites are p-type. ${ }^{40,41} \mathrm{We}$ hence assume that our perovskite layer is also p-type. The negative capacitance change is therefore assigned to the migration of bromide ions within the perovskite bulk. ${ }^{27}$ Previously, we have found both iodide and methylammonium migrating in $\mathrm{MAPbI}_{3}$ perovskites. The absence of a positive capacitance transient indicates that the migration of methylammonium is inhibited in the samples studied here.

To quantify ion migration, we fit the capacitance transient using exponential decay functions. Using an Arrhenius plot, both $E_{\mathrm{A}}$ and $D_{0}$ can be obtained (see Figure $3 \mathrm{c}$ ). At low temperatures, observed thermal emission rates deviate from the fitted line. This might be due to the occurrence of both mobile ions and trap states at low temperatures, which could lead to complex interactions between the two (see Supporting Information Section S4 for details). The activation energies and diffusion coefficients for ion migration are shown in Figure $4 \mathrm{a}, \mathrm{b}$ and summarized in Table 1 .

As in impedance spectroscopy, we find that $\mathrm{Mn}^{2+}$ doping increases the activation energy from $0.14 \pm 0.01$ to $0.30 \pm 0.01$ $\mathrm{eV}$, which we can now assign to migration of bromide within the perovskite bulk. The activation energy of $0.14 \mathrm{eV}$ for the migration of bromide in undoped $\mathrm{PEABr}_{0.2} \mathrm{Cs}_{0.4} \mathrm{MA}_{0.6} \mathrm{PbBr}_{3}$ is very close to theoretically predicted activation energies for 

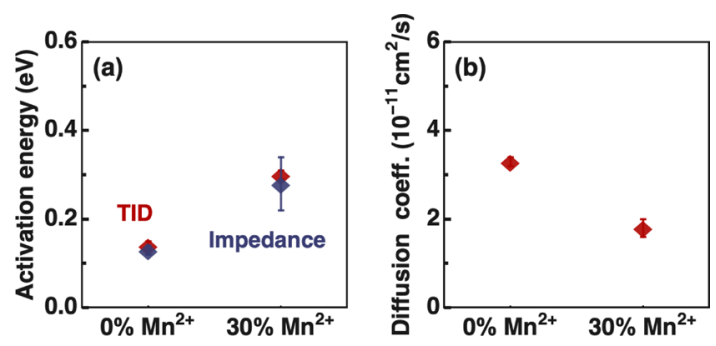

Figure 4. Effect of $\mathrm{Mn}^{2+}$ doping on mobile ions. (a) Activation energy and (b) diffusion coefficient at $300 \mathrm{~K}$ obtained by TID (red) and impedance spectroscopy (blue) measurements. The values of TID measurements are summarized in Table 1 .

Table 1. Summary of Results Obtained Using TID Measurements $^{a}$

$\begin{array}{lcc} & \text { activation energy }(\mathrm{eV}) & \text { diffusion coefficient }\left(\mathrm{cm}^{2} / \mathrm{s}\right) \\ \text { undoped } & 0.14 \pm 0.01 & (3.3 \pm 0.1) \times 10^{-11} \\ \mathrm{Mn}^{2+} \text {-doped } & 0.30 \pm 0.01 & (1.8 \pm 0.2) \times 10^{-11}\end{array}$

${ }^{a}$ See Supporting Information Section S5 for results from individual measurements.

bromide in $\mathrm{MAPbBr}_{3}(0.09 \mathrm{eV})^{42}$ and consistent with measured activation energies in $\mathrm{CsPbBr}_{3}(0.09-0.25 \mathrm{eV}){ }^{43,44}$

Even though the activation energy for ion migration increases twofold, we find only a small decrease in the diffusion coefficient from $(3.3 \pm 0.1) \times 10^{-11}$ to $(1.8 \pm 0.2) \times$ $10^{-11} \mathrm{~cm}^{2} / \mathrm{s}$ upon $\mathrm{Mn}^{2+}$ doping. This is due to a strong increase of the prefactor $D_{0}$ by 3 orders of magnitude from $10^{-6}$ to $10^{-3} \mathrm{~cm}^{2} / \mathrm{s}$ upon $\mathrm{Mn}^{2+}$ doping (see Supporting Information Section S5). We assume that this increase in prefactor is due to an increase in the attempt frequency $\nu_{0}$ and migration entropy $\Delta S$ that depends on the change in lattice vibrations during migration. ${ }^{45}$ It has previously been shown that decreasing the phonon density of states in ionic conductors decreases the activation energy for ion migration but at the same time increases both the attempt frequency $\nu_{0}$ and the migration entropy $\Delta S$, resulting in a trade-off between the activation energy $E_{\mathrm{A}}$ and the prefactor $D_{0} \cdot{ }^{46,47}$ We hence suspect that $\mathrm{Mn}^{2+}$ doping leads to an increase in the phonon density of states compared to the undoped case. This change in phonon density might be due to the weaker bond between $\mathrm{Pb}^{2+}$ and $\mathrm{Br}^{-}$than between $\mathrm{Mn}^{2+}$ and $\mathrm{Br}^{-}$or because of the smaller ionic radius of $\mathrm{Mn}^{2+}(\sim 0.97 \AA)$ compared to $\mathrm{Pb}^{2+}$ $(\sim 1.33 \AA),{ }^{25}$ which stabilizes the perovskite lattice and reduces the migration of mobile ions.

The obtained diffusion coefficient in the order $10^{-11} \mathrm{~cm}^{2} / \mathrm{s}$ for mobile bromides is 2 orders of magnitude lower than typical diffusion coefficients of $10^{-9} \mathrm{~cm}^{2} / \mathrm{s}$ obtained for iodide in $\mathrm{MAPbI}_{3}{ }^{37}$ but close to the diffusion coefficient for iodide in 2D perovskites $\left(10^{-10} \mathrm{~cm}^{2} / \mathrm{s}\right)$ and for bromide in $\mathrm{MAPbBr}_{3}$ single crystals $\left(10^{-11} \mathrm{~cm}^{2} / \mathrm{s}\right),{ }^{48,49}$ which shows that the diffusion coefficient depends strongly on the perovskite composition. We furthermore find a concentration of mobile ions in the order of $10^{16} \mathrm{~cm}^{-3}$, which corresponds to about $10 \%$ of the effective doping density (see Supporting Information Section S5). The diffusion coefficient and the activation energy are highly reproducible in our devices, whereas the ion concentration varies from sample to sample (see Supporting Information Section S5). This trend indicates that the fabrication conditions determine the density of halide vacancies responsible for ion migration ${ }^{49,50}$ but that the bulk properties such as $E_{\mathrm{A}}$ and $D$ are largely independent of the mobile ion density.

We note that only with TID measurements, the sign of the mobile ion species can be measured and can be used to directly extract the diffusion coefficient of mobile ions. ${ }^{27}$ To extract the diffusion coefficient with impedance spectroscopy measurements, the diffusion length of the ions must be known. In eq 3 , we estimated the diffusion length to be equal to the Debye length. Knowing the diffusion coefficient from TID measurements, we can verify this assumption by calculating the diffusion length from our impedance spectroscopy measurements using eq 1 . We obtain a diffusion length of $5.7 \pm 0.7 \mathrm{~nm}$ for both the undoped and $\mathrm{Mn}^{2+}$-doped cases. This is close to the calculated Debye length of $4.0 \pm 0.4 \mathrm{~nm}$ using doping densities and dielectric permittivities from the Mott-Schottky analysis. We therefore assume that the assumption that diffusion is restricted to the Debye layer is approximately valid in our case. However, this is not necessarily true for every system.

Because the degradation of perovskite LEDs is mainly related to their mixed ionic-electronic nature, ${ }^{6}$ we suspect that the suppression of ion migration is the reason for the increased stability of the $\mathrm{Mn}^{2+}$-doped devices. We furthermore suspect that the increased activation energy for ion migration within the perovskite lattice suggests a reduced migration of ions from the electrodes, that is $\mathrm{Au}, \mathrm{In}$, or $\mathrm{Sn}^{51,52}$ into the perovskite bulk, which is another significant degradation pathway of perovskite LEDs.

The increase in performance and stability due to $\mathrm{Mn}^{2+}$ doping is not limited to perovskite-based LEDs but also applies to perovskite-based solar cells. ${ }^{53}$ Presumably, in all these materials, replacing $\mathrm{Pb}^{2+}$ with $\mathrm{Mn}^{2+}$ leads to a stronger metalhalide bond giving rise to an increase in the activation energy and attempt frequency. We therefore expect that $\mathrm{Mn}^{2+}$ doping is a transferable method to improve the stability of perovskitebased optoelectronic devices by reducing ion migration in these devices.

\section{CONCLUSIONS}

We have investigated the effect of $\mathrm{Mn}^{2+}$ doping on mobile ions in $\mathrm{PEABr}_{0.2} \mathrm{Cs}_{0.4} \mathrm{MA}_{0.6} \mathrm{PbBr}_{3}$ perovskites. $\mathrm{Mn}^{2+}$ doping improves both efficiency and long-term stability in LEDs made from these materials. Using temperature-dependent impedance spectroscopy and TID measurements, we found that $\mathrm{Mn}^{2+}$ doping leads to a twofold increase in activation energy, which is accompanied by an increase in the attempt frequency and migration entropy of mobile bromide ions within the bulk of the perovskite. This change results in a small reduction of the diffusion coefficient. We suspect that this increased activation energy for ion migration within the perovskite bulk reduces migration of ions from the contact layers into the perovskite bulk. These results help to explain the improved stability of manganese-doped LEDs and lead to a better understanding of the influence of passivating agents on managing ion migration, thus improving the stability of perovskite devices.

\section{EXPERIMENTAL SECTION}

Device Fabrication. The perovskite devices were fabricated by following the same procedures described in our previous work. ${ }^{1,2}$ Briefly, a thin layer of PEDOT:polystyrene sulfonate (Clevios PVP Al 4083 ) was spun at $4000 \mathrm{rpm}$ for $40 \mathrm{~s}$ with a ramp of $2500 \mathrm{rpm} / \mathrm{s}$ on cleaned ITO substrates, followed by a thin layer of PFI (Nafion) spun at $3000 \mathrm{rpm}$ for $45 \mathrm{~s}$ using $10 \mu \mathrm{L} / \mathrm{mL}$ PFI in isopropanol. After 
drying, the perovskite layer was spun from $0.3 \mathrm{M}$ precursors in an appropriate ratio to make $\mathrm{PEA}_{0.2} \mathrm{Br}_{0.2} \mathrm{Cs}_{0.4} \mathrm{MA}_{0.6} \mathrm{~Pb}_{(1-y)} \mathrm{Mn}_{y} \mathrm{Br}_{3}$, where $y=0$ and 0.3 at $1000 \mathrm{rpm}$ for $10 \mathrm{~s}$ and $3000 \mathrm{rpm}$ for $45 \mathrm{~s}$; after $20 \mathrm{~s}$, $90 \mu \mathrm{L}$ of chloroform was dripped to control the crystallization. Finally, $40 \mathrm{~nm} \mathrm{TPBi}, 1.1 \mathrm{~nm} \mathrm{LiF}$, and $60 \mathrm{~nm} \mathrm{Al}$ were deposited consecutively in an evaporation chamber. To fabricate devices consisting of $\mathrm{NiO}_{X} /$ perovskite $/ \mathrm{C}_{60} / \mathrm{BCP}, \mathrm{NiO}_{X}$ was spun at $2500 \mathrm{rpm}$ with a ramp of $2500 \mathrm{rpm} / \mathrm{s}$ on clean ITO substrates. After annealing at $300{ }^{\circ} \mathrm{C}$ for 3 $\mathrm{h}$, the perovskite layer was spun in the same way as for the LEDs.

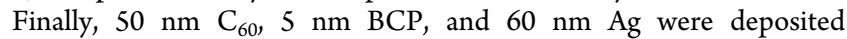
consecutively in an evaporation chamber.

Device Characterization. The devices were packed using epoxy and glass before performing any measurements outside the glovebox. Current density-voltage-luminance curves were measured using an HP4145A analyzer and a calibrated half-inch ThorLabs photodiode. Electroluminescence spectra were taken with an Ocean Optics QE Pro spectrometer at $0.5 \mathrm{~mA}$ supplied by a Keithley 2400 sourcemeasure unit. Stability curves were determined by measuring the electroluminescence over time at a constant current.

Electrical Measurements. The measurements were performed in a Janis VPF-100 liquid nitrogen cryostat at a pressure below $2 \times 10^{-6}$ mbar in the dark using a DLTS system from Semetrol. Capacitance transient measurements were performed between 240 and $340 \mathrm{~K}$ in steps of $2-3 \mathrm{~K}$. Before each capacitance transient measurement, the temperature was maintained for at least $1 \mathrm{~min}$ with an accuracy of 0.2 $K$. The capacitance transients were averaged over 20 scans. Impedance spectroscopy measurements were performed between 240 and $340 \mathrm{~K}$ in steps of $10 \mathrm{~K}$ with an AC voltage of $50 \mathrm{mV}$. Before each impedance spectroscopy measurement, the temperature was maintained for at least $5 \mathrm{~min}$ with an accuracy of $0.2 \mathrm{~K}$. The capacitance was calculated assuming a capacitor in parallel with a resistor.

\section{ASSOCIATED CONTENT}

\section{(s) Supporting Information}

The Supporting Information is available free of charge at https://pubs.acs.org/doi/10.1021/acsaelm.0c00125.

Impedance spectroscopy measurements, mobile ions versus trap states, Mott-Schottky characteristics, fitting of capacitance transients, and TID measurements (PDF)

\section{AUTHOR INFORMATION}

\section{Corresponding Author}

Bruno Ehrler - AMOLF, Center for Nanophotonics, 1098 XG Amsterdam, The Netherlands; (1) orcid.org/0000-0002-53073241; Email: ehrler@amolf.nl

\section{Authors}

Moritz H. Futscher - AMOLF, Center for Nanophotonics, 1098 XG Amsterdam, The Netherlands; 아. orcid.org/00000001-8451-5009

Mahesh K. Gangishetty - Rowland Institute at Harvard, Cambridge 02142, Massachusetts, United States

Daniel N. Congreve - Rowland Institute at Harvard, Cambridge 02142, Massachusetts, United States; 이이.org/ 0000-0002-2914-3561

Complete contact information is available at:

https://pubs.acs.org/10.1021/acsaelm.0c00125

\section{Notes}

The authors declare no competing financial interest.

\section{ACKNOWLEDGMENTS}

The authors thank Erik C. Garnett for carefully reading and commenting on the manuscript. This work is part of the Dutch
Research Council (NWO) and was performed at the research institute AMOLF. D.N.C. and M.K.G. acknowledge the support of the Rowland Fellowship at the Rowland Institute at Harvard University.

\section{REFERENCES}

(1) Tan, Z.-K.; Moghaddam, R. S.; Lai, M. L.; Docampo, P.; Higler, R.; Deschler, F.; Price, M.; Sadhanala, A.; Pazos, L. M.; Credgington, D.; Hanusch, F.; Bein, T.; Snaith, H. J.; Friend, R. H. Bright LightEmitting Diodes Based on Organometal Halide Perovskite. Nat. Nanotechnol. 2014, 9, 687-692.

(2) Yuan, M.; Quan, L. N.; Comin, R.; Walters, G.; Sabatini, R.; Voznyy, O.; Hoogland, S.; Zhao, Y.; Beauregard, E. M.; Kanjanaboos, P.; Lu, Z.; Kim, D. H.; Sargent, E. H. Perovskite Energy Funnels for Efficient Light-Emitting Diodes. Nat. Nanotechnol. 2016, 11, 872877.

(3) Wang, N.; Cheng, L.; Ge, R.; Zhang, S.; Miao, Y.; Zou, W.; Yi, C.; Sun, Y.; Cao, Y.; Yang, R.; Wei, Y.; Guo, Q.; Ke, Y.; Yu, M.; Jin, Y.; Liu, Y.; Ding, Q.; Di, D.; Yang, L.; Xing, G.; Tian, H.; Jin, C.; Gao, F.; Friend, R. H.; Wang, J.; Huang, W. Perovskite Light-Emitting Diodes Based on Solution-Processed Self-Organized Multiple Quantum Wells. Nat. Photonics 2016, 10, 699-704.

(4) Yang, X.; Zhang, X.; Deng, J.; Chu, Z.; Jiang, Q.; Meng, J.; Wang, P.; Zhang, L.; Yin, Z.; You, J. Efficient Green Light-Emitting Diodes Based on Quasi-Two-Dimensional Composition and Phase Engineered Perovskite with Surface Passivation. Nat. Commun. 2018, 9, 570

(5) Lin, K.; Xing, J.; Quan, L. N.; de Arquer, F. P. G.; Gong, X.; Lu, J.; Xie, L.; Zhao, W.; Zhang, D.; Yan, C.; Li, W.; Liu, X.; Lu, Y.; Kirman, J.; Sargent, E. H.; Xiong, Q.; Wei, Z. Perovskite LightEmitting Diodes with External Quantum Efficiency Exceeding 20 per Cent. Nature 2018, 562, 245-248.

(6) Cho, H.; Kim, Y.-H.; Wolf, C.; Lee, H.-D.; Lee, T.-W. Improving the Stability of Metal Halide Perovskite Materials and Light-Emitting Diodes. Adv. Mater. 2018, 30, 1704587.

(7) Vashishtha, P.; Halpert, J. E. Field-Driven Ion Migration and Color Instability in Red-Emitting Mixed Halide Perovskite Nanocrystal Light-Emitting Diodes. Chem. Mater. 2017, 29, 5965-5973.

(8) McMeekin, D. P.; Sadoughi, G.; Rehman, W.; Eperon, G. E.; Saliba, M.; Horantner, M. T.; Haghighirad, A.; Sakai, N.; Korte, L.; Rech, B.; Johnston, M. B.; Herz, L. M.; Snaith, H. J. A Mixed-Cation Lead Mixed-Halide Perovskite Absorber for Tandem Solar Cells. Science 2016, 351, 151-155.

(9) Yi, C.; Luo, J.; Meloni, S.; Boziki, A.; Ashari-Astani, N.; Grätzel, C.; Zakeeruddin, S. M.; Röthlisberger, U.; Grätzel, M. Entropic Stabilization of Mixed A-Cation ABX3 Metal Halide Perovskites for High Performance Perovskite Solar Cells. Energy Environ. Sci. 2016, 9, $656-662$.

(10) Geyer, S. M.; Scherer, J. M.; Moloto, N.; Jaworski, F. B.; Bawendi, M. G. Efficient Luminescent Down-Shifting Detectors Based on Colloidal Quantum Dots for Dual-Band Detection Applications. ACS Nano 2011, 5, 5566-5571.

(11) Noh, J. H.; Im, S. H.; Heo, J. H.; Mandal, T. N.; Seok, S. I. Chemical Management for Colorful, Efficient, and Stable InorganicOrganic Hybrid Nanostructured Solar Cells. Nano Lett. 2013, 13, 1764-1769.

(12) Pering, S. R.; Deng, W.; Troughton, J. R.; Kubiak, P. S.; Ghosh, D.; Niemann, R. G.; Brivio, F.; Jeffrey, F. E.; Walker, A. B.; Islam, M. S.; Watson, T. M.; Raithby, P. R.; Johnson, A. L.; Lewis, S. E.; Cameron, P. J. Azetidinium Lead Iodide for Perovskite Solar Cells. J. Mater. Chem. A 2017, 5, 20658-20665.

(13) De Marco, N.; Zhou, H.; Chen, Q.; Sun, P.; Liu, Z.; Meng, L.; Yao, E.-P.; Liu, Y.; Schiffer, A.; Yang, Y. Guanidinium: A Route to Enhanced Carrier Lifetime and Open-Circuit Voltage in Hybrid Perovskite Solar Cells. Nano Lett. 2016, 16, 1009-1016.

(14) Kubicki, D. J.; Prochowicz, D.; Hofstetter, A.; Saski, M.; Yadav, P.; Bi, D.; Pellet, N.; Lewiński, J.; Zakeeruddin, S. M.; Grätzel, M.; Emsley, L. Formation of Stable Mixed Guanidinium-Methylammo- 
nium Phases with Exceptionally Long Carrier Lifetimes for HighEfficiency Lead Iodide-Based Perovskite Photovoltaics. J. Am. Chem. Soc. 2018, 140, 3345-3351.

(15) Kieslich, G.; Sun, S.; Cheetham, A. K. Solid-state principles applied to organic-inorganic perovskites: new tricks for an old dog. Chem. Sci. 2014, 5, 4712-4715.

(16) Ferdani, D. W.; Pering, S. R.; Ghosh, D.; Kubiak, P.; Walker, A. B.; Lewis, S. E.; Johnson, A. L.; Baker, P. J.; Islam, M. S.; Cameron, P. J. Partial Cation Substitution Reduces Iodide Ion Transport in Lead Iodide Perovskite Solar Cells. Energy Environ. Sci. 2019, 12, 22642272.

(17) Zou, S.; Liu, Y.; Li, J.; Liu, C.; Feng, R.; Jiang, F.; Li, Y.; Song, J.; Zeng, H.; Hong, M.; Chen, X. Stabilizing Cesium Lead Halide Perovskite Lattice through $\mathrm{Mn}$ (II) Substitution for Air-Stable LightEmitting Diodes. J. Am. Chem. Soc. 2017, 139, 11443-11450.

(18) Das Adhikari, S.; Guria, A. K.; Pradhan, N. Insights of Doping and the Photoluminescence Properties of Mn-Doped Perovskite Nanocrystals. J. Phys. Chem. Lett. 2019, 10, 2250-2257.

(19) Bera, S.; Ghosh, D.; Dutta, A.; Bhattacharyya, S.; Chakraborty, S.; Pradhan, N. Limiting Heterovalent B-Site Doping in CsPbI3 Nanocrystals: Phase and Optical Stability. ACS Energy Lett. 2019, 4, 1364-1369.

(20) Hou, S.; Gangishetty, M. K.; Quan, Q.; Congreve, D. N. Efficient Blue and White Perovskite Light-Emitting Diodes via Manganese Doping. Joule 2018, 2, 2421-2433.

(21) Gangishetty, M. K.; Sanders, S. N.; Congreve, D. N. Mn2+ Doping Enhances the Brightness, Efficiency, and Stability of Bulk Perovskite Light-Emitting Diodes. ACS Photonics 2019, 6, 11111117.

(22) Cortecchia, D.; Mróz, W.; Neutzner, S.; Borzda, T.; Folpini, G.; Brescia, R.; Petrozza, A. Defect Engineering in 2D Perovskite by $\mathrm{Mn}$ (II) Doping for Light-Emitting Applications. Chem 2019, 5, 2146-2158.

(23) Kooijman; Muscarella, fnm; Williams, fnm Perovskite Thin Film Materials Stabilized and Enhanced by Zinc(II) Doping. Appl. Sci. 2019, 9, 1678.

(24) Mir, W. J.; Jagadeeswararao, M.; Das, S.; Nag, A. Colloidal MnDoped Cesium Lead Halide Perovskite Nanoplatelets. ACS Energy Lett. 2017, 2, 537-543.

(25) Liu, W.; Lin, Q.; Li, H.; Wu, K.; Robel, I.; Pietryga, J. M.; Klimov, V. I. Mn2+-Doped Lead Halide Perovskite Nanocrystals with Dual-Color Emission Controlled by Halide Content. J. Am. Chem. Soc. 2016, 138, 14954-14961.

(26) Parobek, D.; Roman, B. J.; Dong, Y.; Jin, H.; Lee, E.; Sheldon, M.; Son, D. H. Exciton-to-Dopant Energy Transfer in Mn-Doped Cesium Lead Halide Perovskite Nanocrystals. Nano Lett. 2016, 16, $7376-7380$.

(27) Futscher, M. H.; Gangishetty, M. K.; Congreve, D. N.; Ehrler, B. Quantifying mobile ions and electronic defects in perovskite-based devices with temperature-dependent capacitance measurements: Frequency vs time domain. J. Chem. Phys. 2020, 152, 044202.

(28) Bisquert, J.; Garcia-Belmonte, G.; Guerrero, A. Impedance Characteristics of Hybrid Organometal Halide Perovskite Solar Cells. Organic-Inorganic Halide Perovskite Photovoltaics: From Fundamentals to Device Architectures; Springer International Publishing: Cham, 2016; pp 163-199.

(29) Pitarch-Tena, D.; Ngo, T. T.; Vallés-Pelarda, M.; Pauporté, T.; Mora-Seró, I. Impedance Spectroscopy Measurements in Perovskite Solar Cells: Device Stability and Noise Reduction. ACS Energy Lett. 2018, 3, 1044-1048.

(30) Von Hauff, E. Impedance Spectroscopy for Emerging Photovoltaics. J. Phys. Chem. C 2019, 123, 11329-11346.

(31) Wang, H.; Guerrero, A.; Bou, A.; Al-Mayouf, A. M.; Bisquert, J. Kinetic and Material Properties of Interfaces Governing Slow Response and Long Timescale Phenomena in Perovskite Solar Cells. Energy Environ. Sci. 2019, 12, 2054-2079.

(32) Bisquert, J. Nanostructured Energy Devices: Equilibrium Concepts and Kinetics; CRC Press, 2015.
(33) Guerrero, A.; Garcia-Belmonte, G.; Mora-Sero, I.; Bisquert, J.; Kang, Y. S.; Jacobsson, T. J.; Correa-Baena, J.-P.; Hagfeldt, A. Properties of Contact and Bulk Impedances in Hybrid Lead Halide Perovskite Solar Cells Including Inductive Loop Elements. J. Phys. Chem. C 2016, 120, 8023-8032.

(34) Zamouche, A.; Heiser, T.; Mesli, A. Investigation of Fast Diffusing Impurities in Silicon by a Transient Ion Drift Method. Appl. Phys. Lett. 1995, 66, 631.

(35) Heiser, T.; Weber, E. R. Transient Ion-Drift-Induced Capacitance Signals in Semiconductors. Phys. Rev. B 1998, 58, 3893-3903.

(36) Kiermasch, D.; Philipp, R.; Tvingstedt, K.; Andreas, B.; Vladimir, D. Improved Charge Carrier Lifetime in Planar Perovskite Solar Cells by Bromine Doping. Sci. Rep. 2016, 6, 1234-1237.

(37) Futscher, M. H.; Lee, J. M.; McGovern, L.; Muscarella, L. A.; Wang, T.; Haider, M. I.; Fakharuddin, A.; Schmidt-Mende, L.; Ehrler, B. Quantification of Ion Migration in CH3NH3PbI3 Perovskite Solar Cells by Transient Capacitance Measurements. Mater. Horiz. 2019, 6, 1497-1503.

(38) Heiser, T.; Mesli, A. Determination of the Copper Diffusion Coefficient in Silicon from Transient Ion-Drift. Appl. Phys. A: Solids Surf. 1993, 57, 325-328.

(39) Yuan, Y.; Wang, Q.; Shao, Y.; Lu, H.; Li, T.; Gruverman, A.; Huang, J. Electric-Field-Driven Reversible Conversion between Methylammonium Lead Triiodide Perovskites and Lead Iodide at Elevated Temperatures. Adv. Energy Mater. 2016, 6, 1501803.

(40) Zhang, H.; Liu, X.; Dong, J.; Yu, H.; Zhou, C.; Zhang, B.; Xu, Y.; Jie, W. Centimeter-Sized Inorganic Lead Halide Perovskite CsPbBr3 Crystals Grown by an Improved Solution Method. Cryst. Growth Des. 2017, 17, 6426-6431.

(41) Musiienko, A.; Moravec, P.; Grill, R.; Praus, P.; Vasylchenko, I.; Pekarek, J.; Tisdale, J.; Ridzonova, K.; Belas, E.; Landová, L.; Hu, B.; Lukosi, E.; Ahmadi, M. Deep Levels, Charge Transport and Mixed Conductivity in Organometallic Halide Perovskites. Energy Environ. Sci. 2019, 12, 1413-1425.

(42) Azpiroz, J. M.; Mosconi, E.; Bisquert, J.; De Angelis, F. Defect Migration in Methylammonium Lead Iodide and Its Role in Perovskite Solar Cell Operation. Energy Environ. Sci. 2015, 8, $2118-2127$

(43) Mizusaki, J.; Arai, K.; Fueki, K. Ionic Conduction of the Perovskite-Type Halides. Solid State Ionics 1983, 11, 203-211.

(44) Cho, H.; Wolf, C.; Kim, J. S.; Yun, H. J.; Bae, J. S.; Kim, H.; Heo, J.-M.; Ahn, S.; Lee, T.-W. High-Efficiency Solution-Processed Inorganic Metal Halide Perovskite Light-Emitting Diodes. Adv. Mater. 2017, 29, 1700579.

(45) Schoonman, J. The Ionic Conductivity of Pure and Doped Lead Bromide Single Crystals. J. Solid State Chem. 1972, 4, 466-474.

(46) Kraft, M. A.; Culver, S. P.; Calderon, M.; Böcher, F.; Krauskopf, T.; Senyshyn, A.; Dietrich, C.; Zevalkink, A.; Janek, J.; Zeier, W. G. Influence of Lattice Polarizability on the Ionic Conductivity in the Lithium Superionic Argyrodites Li6PS5X $(\mathrm{X}=\mathrm{Cl}, \mathrm{Br}, \mathrm{I})$. J. Am. Chem. Soc. 2017, 139, 10909-10918.

(47) Krauskopf, T.; Muy, S.; Culver, S. P.; Ohno, S.; Delaire, O.; Shao-Horn, Y.; Zeier, W. G. Comparing the Descriptors for Investigating the Influence of Lattice Dynamics on Ionic Transport Using the Superionic Conductor Na 3 PS 4-x Se X. J. Am. Chem. Soc. 2018, 140, 14464-14473.

(48) Li, C.; Wang, N.; Guerrero, A.; Zhong, Y.; Long, H.; Miao, Y.; Bisquert, J.; Wang, J.; Huettner, S. Understanding the Improvement of Stability in Self-Assembled Multiple Quantum Wells Perovskite Light-Emitting Diode. J. Phys. Chem. Lett. 2019, 10, 6857.

(49) Luo, Y.; Khoram, P.; Brittman, S.; Zhu, Z.; Lai, B.; Ong, S. P.; Garnett, E. C.; Fenning, D. P. Direct Observation of Halide Migration and Its Effect on the Photoluminescence of Methylammonium Lead Bromide Perovskite Single Crystals. Adv. Mater. 2017, 29, 1703451.

(50) Senocrate, A.; Moudrakovski, I.; Kim, G. Y.; Yang, T.-Y.; Gregori, G.; Grätzel, M.; Maier, J. The Nature of Ion Conduction in Methylammonium Lead Iodide: A Multimethod Approach. Angew. Chem., Int. Ed. 2017, 56, 7755-7759. 
(51) Domanski, K.; Correa-Baena, J.-P.; Mine, N.; Nazeeruddin, M. K.; Abate, A.; Saliba, M.; Tress, W.; Hagfeldt, A.; Grätzel, M. Not All That Glitters Is Gold: Metal-Migration-Induced Degradation in Perovskite Solar Cells. ACS Nano 2016, 10, 6306-6314.

(52) Seo, H.-K.; Kim, H.; Lee, J.; Park, M.-H.; Jeong, S.-H.; Kim, Y.H.; Kwon, S.-J.; Han, T.-H.; Yoo, S.; Lee, T.-W. Efficient Flexible Organic/Inorganic Hybrid Perovskite Light-Emitting Diodes Based on Graphene Anode. Adv. Mater. 2017, 29, 1605587.

(53) Liu, W.; Chu, L.; Liu, N.; Ma, Y.; Hu, R.; Weng, Y.; Li, H.; Zhang, J.; Li, X. a.; Huang, W. Efficient Perovskite Solar Cells Fabricated by Manganese Cations Incorporated in Hybrid Perovskites. J. Mater. Chem. C 2019, 7, 11943-11952. 